\title{
СОВЕРШЕНСТВОВАНИЕ ТЕХНОЛОГИИ ПЕРЕРАБОТКИ СУНГУЛИТ-ВЕРМИКУЛИТОВЫХ КОНГЛОМЕРАТОВ
}

\author{
Нижегородов Анатолий Иванович', \\ nastromo_irkutsk@mail.ru \\ Гаврилин Алексей Николаевич², \\ tom-gawral@list.ru \\ Мойзес Борис Борисович², \\ mbb@tpu.ru
Иркутский национальный исследовательский технический университет, Россия, 664074, г. Иркутск, ул. Лермонтова, 83.
2 Национальный исследовательски Томский политехнический университет, \\ Россия, 634050, г. Томск, пр. Ленина, 30.
}

\begin{abstract}
Актуальность. Усовершенствованная энерго- и ресурсосберегающая технология, реализуемая в новых технологических комплексах с предварительным “холодным» дообогащением, позволяет вернуть в промышленный оборот ценные сырьевые ресурсы и получить вермикулитовые и сунгулитовые концентраты из горнопромышленных отходов, накопленных на Ковдорском флогопит-вермикулитовом месторождении. В связи с этим данная работа посвящена вопросам совершенствования технологии переработки сунгулит-вермикулитовых конгломератов.

Цель: анализ возможности совершенствования технологии получения термоактивированного сунгулита и вспученного вермикулита из горно-промышленных отходов Ковдорского флогопит-вермикулитового месторождения и повышение ее энергоэффективности.

Объект: технологическое оборудование по переработке сунгулит-вермикулитовых конгломератов, реализующее энерго- и ресурсосберегающую технологию получения активированного сунгулита и вермикулитового концентрата.

Методы исследования базируются на экспериментальных данных и анализе процессов аэродинамического отделения вермикулита и сунгулита от оливин-пироксеновой породы и повышения доли сунгулита в сунгулит-вермикулитовом концентрате. Результаты подтверждают достижение цели исследования. На их основе можно создать усовершенствованную технологию получения вермикулита, в том числе вспученного и магнезиально-силикатного реагента (термоактивированный сунгулит) из горно-промышленных отходов с экономией энергии до 182 кДж/кг, что уменьшает энергоемкость их переработки на 28 \% по сравнению спредшествующей технологией. Кроме того, дополнительные технологические операции позволяют получить 350 кг вермикулита-сырца, 68 кг чистого магнезиально-силикатного реагента с размерами зерен 2,4...3,5 мм и 158 кг сунгулитового концентрата в термоактивированном виде с зернами 1,3...2,4 мм при почти 86 процентной концентрации. В целом можно сделать вывод о перспективности продолжения работ в области развития и совершенствования технологий переработки сунгулит-вермикулитовых конгломератов.
\end{abstract}

\section{Ключевые слова:}

Сунгулит-вермикулитовый конгломерат, сунгулит, вермикулит, пироксен-оливиновая порода, термоактивация, обжиг, разделение компонентов, скорость витания, технологический комплекс, “холодное» дообогащение, тепловая энергия.

\section{Введение}

Вермикулит и материалы на его основе, благодаря своим полезным свойствам, нашли широкое применение во многих сферах деятельности (охрана природы, металлургия, строительство и другие) [1-7], поэтому интерес к технологиям их получения высок.

За многие годы разработки Ковдорского флогопит-вермикулитового месторождения в заскладированных вскрышных породах и хвостохранилищах накопились сотни тысяч тонн высококачественного вермикулита и сопутствующего ему сунгулита, минерала из серпентиновой группы [8]. Технология обогащения этих горно-промышленных отходов, разработанная в горном институте Кольского научного центра, позволяет получить сунгулит-вермикулитовый конгломерат, в котором, кроме вермикулита и сунгулита, являющих- ся ценным сырьем для получения вспученного вермикулита и магнезиально-силикатного реагента $[9,10]$, содержится и оливин-пироксеновая фаза (рис. 1), подлежащая утилизации.

В работе [11] авторами настоящей статьи была представлена технология выделения этих целевых продуктов из сунгулит-вермикулитового конгломерата при обжиге в электрических модульно-спусковых печах. Специфика процесса термоактивации сунгулита состояла в том, что одновременно с ним подвергались обжигу оливин-пироксеновая фаза и вермикулит, входящие в состав конгломерата.

Поглощаемая вермикулитом теплота за 2,8...3,2 с приводит к дегидратации, выделению химически связанной воды и механической трансформации - вспучиванию его зерен. Остается отделить готовый вспученный продукт от остального материала - каменного гранулята (сунгулита, пи- 


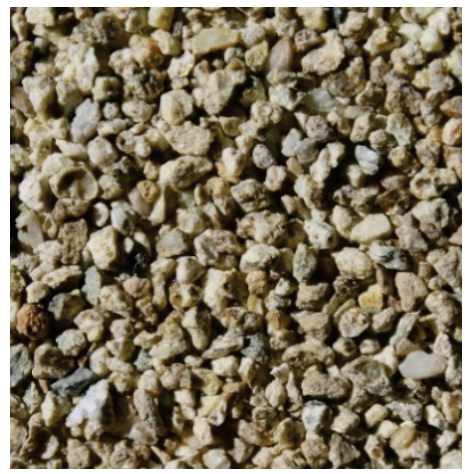

a

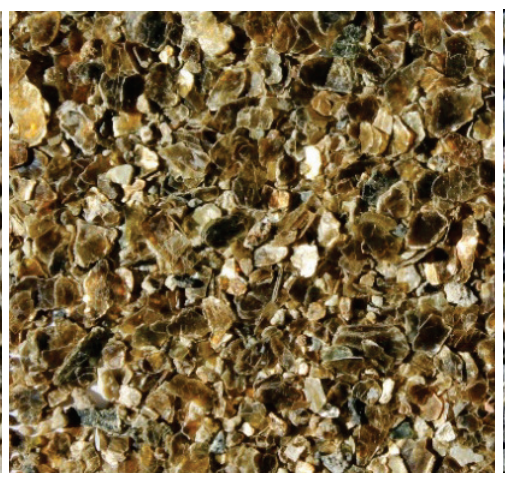

б

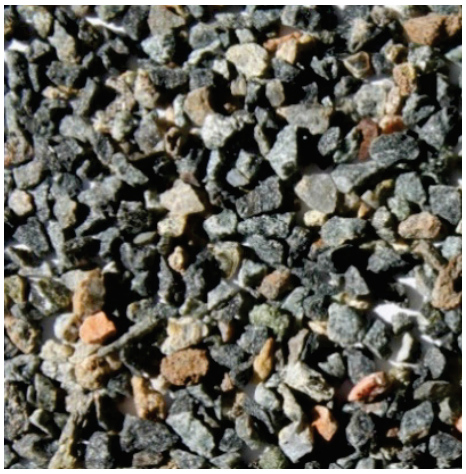

B

Рис. 1. Колпоненты конгломерата: а, б) иелевые продукты-вермикулит и сунгулит, в) оливин-пироксеновая порода

Fig. 1. Conglomerate components: $a, b)$ target products - vermiculite and sungulite, $c$ ) olivine-pyroxene rock

роксена и оливина), например, методом отдува или высасывания из общего потока.

Термоактивация сунгулита - это его быстрое нагревание до температуры $700 \ldots 720{ }^{\circ} \mathrm{C}$ с последующей выдержкой в течение $20 . .225$ минут в термоизолированном бункере при температуре не ниже $600{ }^{\circ} \mathrm{C}[8,10]$. Поскольку конгломерат содержит $34 \ldots 36 \%$ вермикулита, $23 . . .25 \%$ сунгулита и более всего оливин-пироксеновой породы $\sim 39 . .43 \%$ [12], то нагревание в печи всего объема сыпучего материала нецелесообразно, так как более 40 \% конгломерата, нагреваясь, рассеивает накопленное тепло в окружающую среду, а это прямые затраты энергии.

Насыпная плотность необожженного сунгулита составляет 1026 кг $/ \mathrm{m}^{3}$, и он на $21 \%$ легче оливин-пироксеновая фазы ( 1300 кг/ $\left.\mathrm{m}^{3}\right)$, но после термоактивации сунгулит дополнительно теряет в мacce $15 \ldots 18 \%$ из-за выхода гидратной воды, а оливин-пироксеновая порода легче не становится $[8,10,11,13]$. Эти обстоятельства позволяют оптимизировать процессы получения активированного сунгулита и вспученного вермикулита из исходного сырья в едином технологическом комплексе.

Целью исследований стал анализ возможности совершенствования технологии получения термоактивированного сунгулита и вспученного вермикулита из горно-промышленных отходов Ковдорского флогопит-вермикулитового месторождения с последующим повышением ее энергоэффективности.

Объектом исследований в данной работе является технологическое оборудование по переработке сунгулит-вермикулитовых конгломератов, peaлизующее энерго- и ресурсосберегающую технологию получения активированного сунгулита и вермикулитового концентрата.

\section{Экспериментальные исследования}

Основная задача исследований состояла в разделении компонентов конгломерата до их термической обработки, чтобы вывести из дальнейшей переработки оливин-пироксеновую породу, не нагревая ее в печи.
В связи с тем, что компоненты отличаются насыпной плотностью, рассматривались два варианта: - разделение (сегрегация) частиц в слое сыпучего материала под действием вибрации;

- разделение частиц в потоке воздуха по скорости витания.

Известно, что под действием вибрации (псевдо ожижение) сыпучие материалы могут разделяться по [14-16]:

- плотности, если это смесь частиц различной плотности, более легкие «всплывают»;

- крупности, если частицы материала одной природы, более крупные постепенно заполняют верхние слои.

Для проведения экспериментов использовался конгломерат с размером частиц слюды $1,3 . .4$ мм, частиц сунгулита и оливин-пироксеновой породы $1,3 \ldots 3,5$ мм (большее значение максимального размера слюды обусловлено прохождением плоских частиц слюды по диагонали ячеек проволочных сит).

Опыты по вибросегрегации частиц-компонентов исходного конгломерата проводились на вибростоле ВИМ-0,2-25M (000 «Испытательные машины», г. Армавир, Россия) с диапазоном регулирования по частоте $5 . . .25$ Гц и амплитудой виброперемещения 0,8 мм.

В диапазоне частот $5 . .20$ Гц вибрация не вызывала никаких изменений в массиве сыпучего материала, находившегося в стальном цилиндре, хотя при частоте 20 Гц $(125,6$ рад/с) пиковое значение виброускорения $\left(12,6 \mathrm{~m} / \mathrm{c}^{2}\right)$ уже превышало ускорение свободного падения на $28 \%$. Частицы приходили в слабое хаотичное движение, но разделение не происходило.

При увеличении частоты возбуждения от 20 до 25 Гц наблюдалась незначительная тенденция к выходу частиц вермикулитовой слюды на поверхность, а при приближении к 25 Гц (пиковое виброускорение 19,7 м/ $\mathrm{c}^{2}$ ) начиналось виброперемешивание.

Кроме того, во всем диапазоне частот не наблюдалось и разделения по крупности, хотя наиболее крупные частицы конгломерата превышали по размерам самые мелкие. 
Последующие опыты, проведенные с конгломератом сунгулит-оливин-пироксеновой породы, не дали новых результатов. Стало очевидно, что разность насыпных плотностей незначительна для проявления эффекта вибросегрегации.

Дальнейшие эксперименты по разделению частиц-компонентов проводились в потоке воздуха по скорости их витания.

При обзоре многочисленных источников информации, например [3, $4,17,18]$, данных по значениям скорости витания частиц интересующих авторов минералов найти не удалось, поэтому была сконструирована экспериментальная установка (рис. 2).

Экспериментальная установка содержит воздуховод -1 внутренним диаметром $d=0,04$ м и высотой $H=1,0$ м, лоток - 2 для сбрасывания частицкомпонентов, установленный на высоте $h=0,94 \mathrm{M}$, шиберную заслонку - 3, размещенную над лотком, прибор для измерения скорости воздушного потока - анемометр - 4, небольшой сосуд - 5 для сбора выпадающих частиц, рукав-воздухопровод - 6 , фильтр - 7 и вытяжной осевой вентилятор - 8 с регулируемой угловой скоростью вращения рабочего колеса $\omega$.

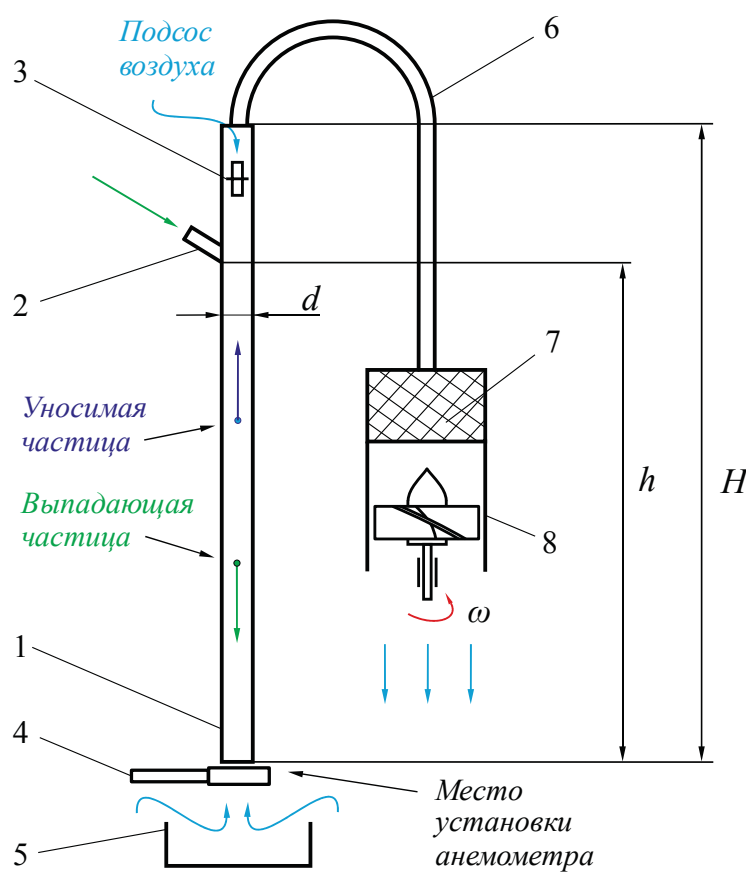

Pис. 2. Схема экспериментальной установки: 1 - воздуховод; 2 лоток; 3 - шиберная заслонка; 4 - анемометр; 5 - сосуд; 6-рукав-воздухопровод; 7 - фильтр; 8-вентилятор осевой

Fig. 2. Diagram of the experimental unit: 1 is the air duct; 2 is the tray; 3 is the gate valve; 4 is the anemometer; 5 is the container; 6 is the air hose; 7 is the filter; 8 is the axial fan

Опыты по определению скорости витания частиц вермикулита, сунгулита и частиц оливин-пироксеновой породы проводились при температуре $\sim 20{ }^{\circ} \mathrm{C}$. Сначала с помощью шибера -3 и регулятора мощности осевого вентилятора - 8 устанавливалась скорость воздуха в воздуховоде - 1 и проводи- лось ее измерение с помощью анемометра AeroTemp X-line X00123 с диаметром зонда измерительной крыльчатки 0,04 м. Начальная скорость составляла $3,4 \mathrm{~m} / \mathrm{c}$.

В каждом опыте через лоток - 2 в воздуховод 1 сбрасывалось по шесть случайно выбранных частиц разных размеров: сначала вермикулита (из диапазона 1,3...4 мм), затем сунгулита и оливинпироксена (1,3...3,5 мм). В некоторых опытах при одной и той же скорости воздуха для большей достоверности шесть частиц-компонентов сбрасывались по два-три раза.

В табл. 1 приведены значения числа выпавших и унесенных потоком частиц вермикулита при различных значениях скорости воздуха $v$.

Таблица 1. Результаты экспериментов с частицами вермикулита

Table 1. Experimental results with vermiculite particles

\begin{tabular}{|c|c|c|}
\hline $\begin{array}{c}\text { Скорость потока } \\
\text { воздуха } v, \mathrm{~m} / \mathrm{c} \\
\begin{array}{c}\text { Air flow rate } v, \\
\mathrm{~m} / \mathrm{s}\end{array}\end{array}$ & $\begin{array}{c}\text { Число выпавших } \\
\text { частиц } \\
\text { Number of fallen } \\
\text { particles }\end{array}$ & $\begin{array}{c}\text { Число унесенных воздухом } \\
\text { частиц (среднее значение) } \\
\text { Number of air entrained } \\
\text { particles (average value) }\end{array}$ \\
\hline 3,8 & 4 & 2 \\
\hline 4,4 & $4 / 3$ & $2 / 3(2,5)$ \\
\hline 6,3 & 3 & 3 \\
\hline 7,6 & 2 & 4 \\
\hline 9,6 & $1 / 2 / 0$ & $5 / 4 / 6(5,0)$ \\
\hline 10,6 & $0 / 0 / 0$ & $6 / 6 / 6(6,0)$ \\
\hline
\end{tabular}

В табл. 2 приведены значения числа выпавших и унесенных потоком частиц сунгулита и оливинпироксеновой породы при различных значениях скорости воздуха $v$ (в скобках даны средние по двум-трем сбрасываниям значения унесенных частиц).

таблица 2. Результаты экспериментов с частицали сунгулита и оливин-пироксеновой породы

Table 2. Experimental results with sungulite particles and olivine-pyroxene rock

\begin{tabular}{|c|c|c|c|c|}
\hline \multirow{2}{*}{ 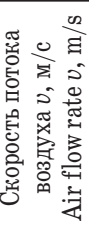 } & \multicolumn{2}{|c|}{$\begin{array}{c}\text { Оливин-пироксеновая порода } \\
\text { Olivine- pyroxene rock }\end{array}$} & \multicolumn{2}{|r|}{$\begin{array}{l}\text { Сунгулит } \\
\text { Sungulite }\end{array}$} \\
\hline & $\begin{array}{c}\text { Выпало } \\
\text { частиц } \\
\text { Number } \\
\text { of fallen } \\
\text { particles }\end{array}$ & \begin{tabular}{|c|} 
Унесено частиц \\
(среднее значение) \\
Number of air en- \\
trained particles \\
(average value)
\end{tabular} & $\begin{array}{c}\text { Выпало } \\
\text { частиц } \\
\text { Number } \\
\text { of fallen } \\
\text { particles }\end{array}$ & $\begin{array}{c}\text { Унесено частиц } \\
\text { (среднее значение) } \\
\text { Number of air en- } \\
\text { trained particles } \\
\text { (average value) }\end{array}$ \\
\hline 3,7 & 6 & 0 & 6 & 0 \\
\hline 6,5 & 6 & 0 & 6 & 0 \\
\hline 7,5 & 6 & 0 & 6 & 0 \\
\hline 9,6 & 6 & 0 & 6 & 0 \\
\hline 12,3 & 6 & 0 & $3 / 3$ & $3 / 3(3)$ \\
\hline 15,4 & $4 / 5$ & $2 / 1(1,5)$ & $4 / 1$ & $2 / 5(3,5)$ \\
\hline 17,5 & $3 / 4 / 2$ & $3 / 2 / 4(3,5)$ & $2 / 1 / 1$ & $4 / 5 / 5(4,67)$ \\
\hline 18,6 & $2 / 3 / 2$ & $4 / 3 / 4(3,67)$ & $1 / 0 / 1$ & $5 / 6 / 5(5,33)$ \\
\hline 20,1 & $1 / 2 / 2$ & $5 / 4 / 4(4,33)$ & $0 / 0 / 0$ & $6 / 6 / 6(6,0)$ \\
\hline 22,9 & $0 / 0 / 1$ & $6 / 6 / 5(5,67)$ & - & - \\
\hline 23,7 & $0 / 0 / 0$ & $6 / 6 / 6(6,0)$ & - & - \\
\hline
\end{tabular}

Из-за потерь на трение в начале и в конце воздуховода возникает разность давлений $\Delta p$. Это вызы- 
вает возрастание скорости потока на выходе, но при $h=0,94$ м падение давления и изменение скорости пренебрежимо малы, поэтому погрешностью измерения скорости витания частиц можно пренебречь.

На рис. 3 показаны зависимости, отражающие количество унесенных потоком воздуха частицкомпонентов конгломерата (по средним значениям табл. 1,2 ) от скорости $v$ на входе в воздуховод (место установки анемометра).

Для частиц-компонентов вермикулитовой слюды все шесть ее частиц были унесены потоком воздуха при скорости $~ 11,0 \mathrm{~m} / \mathrm{c}$ (рис. 3 ), поэтому ориентировочно скорость витания вермикулита можно принять как среднюю из диапазона 9,2...11,0 м/с:

$$
v_{\mathrm{BB}}=10,1 \mathrm{~m} / \mathrm{c} \text {. }
$$

В пневмотранспортных установках расчетную скорость воздуха, обеспечивающую гарантированное перемещение сыпучего материала, принимают на $15 . . .30 \%$ больше, чем скорость витания, но это обусловлено высокой концентрацией частиц, необходимостью достижения наибольшей производительности и наличием горизонтальных участков [19].

В представленной работе речь идет о процессе аэродинамического разделения частиц, поэтому верхний предел скорости (рис. 3) интервала определим как скорость гарантированного отделения (уноса) вермикулита от остальных частиц-компонентов конгломерата $v_{\text {в.y }}=11,0 \mathrm{~m} / \mathrm{c}$.

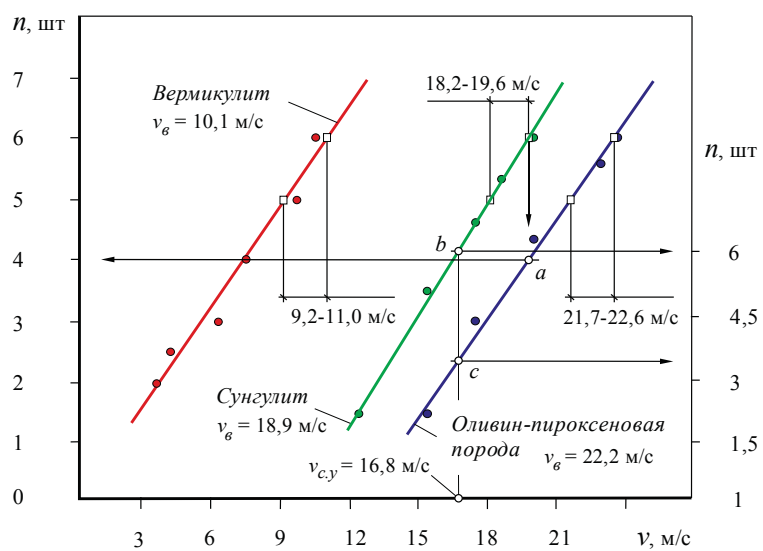

Pис. 3. Зависимости для определения скорости витания компонентов сунгулит-вермикулитовых конгломератов: слюда (1,3...,0 мм ), сунгулит и оливин-пироксеновая порода $\sim(1,3 \ldots 3,5 . \mathrm{Mm})$

Fig. 3. Dependencies for determining soaring speed of sungulite-vermiculite conglomerates components: mica $\sim(1,3 . . .4,0 \mathrm{~mm})$, sungulite and olivine-pyroxene rock $\sim(1,3 . . .3,5 \mathrm{~mm})$

Очевидно, что отделение вермикулита в аэродинамическом устройстве будет максимально эффективным, так как скорость витания сунгулита на $87 \%$ больше, а оливин-пироксеновой фазы - больше в два раза. При этом уносимый воздухом вермикулит практически не будет содержать никаких других частиц-компонентов.

Для сунгулита скорость витания составила $v_{\mathrm{B}}=18,9 \mathrm{M} / \mathrm{c}$, а частиц оливин-пироксеновой поро- ды $-22,2$ м/с (рис. 3), что на 17,5 \% больше, чем для сунгулита.

Эти данные получены для самых крупных по размеру частиц - 3,5 мм. Чтобы обобщить результаты, необходимо получить аналитическую зависимость скоростей витания сунгулита и оливинпироксеновой фазы от условных диаметров частиц из диапазона $1,3 \ldots 3,5$ мм.

Теоретически скорость витания определяется из условия равновесия частицы в потоке воздуха в вертикальном воздухопроводе [19]:

$$
v_{\mathrm{B}}=5,31 \sqrt{D_{\mathrm{y}} \frac{\rho_{\mathrm{M}}}{\rho_{\mathrm{B}}}},
$$

где 5,31 - эмпирический коэффициент с размерностью $(\mathrm{M})^{1 / 2} / \mathrm{c} ; \rho_{\mathrm{m}}-$ истинная плотность материала, $\kappa г / \mathrm{M}^{3} ; \rho_{\text {в }}$ - плотность воздуха, для всасывающих воздуховодов $\rho_{\text {в }} \approx 0,95$ кг/ $\mathrm{M}^{3}[19] ; D_{\text {у }}-$ условный диаметр частицы, м.

Условный диаметр частицы определяется по формуле:

$$
D_{\text {y }}=\sqrt[3]{a_{1} \cdot a_{2} \cdot a_{3}},
$$

где $a_{1}, a_{2}$ и $a_{3}$ - три произвольно измеренных размера частицы, м.

Истинные средние плотности сунгулита и оливин-пироксеновой породы составляют соответственно: 2550, 3500 кг/ $\mathrm{M}^{3}[20]$.

Задавая значения условного диаметра в диапазоне $1,0 \ldots 4,0$ мм, построим расчетные зависимости 1 и 2 (рис. 4).

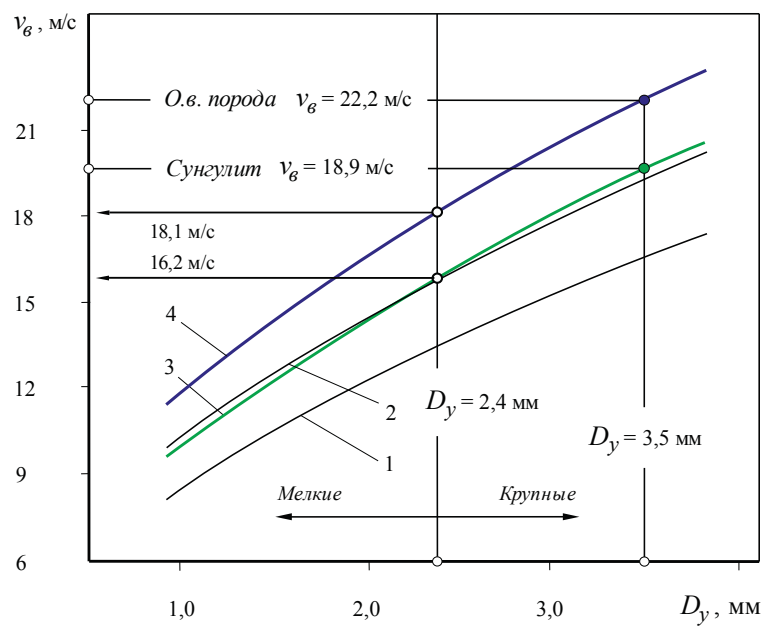

Pис.4. Зависилости скорости витания частии сунгулита и оливин-пироксеновой породы от их условных диаметров: 1,2 - расчетные; 3, 4- экспериментально откорректированные

Fig. 4. Dependences of soaring speed of sungulite and olivine-pyroxene rock particles on their nominal diameters: 1,2 - calculated; 3,4-experimentally corrected

Для частиц условным диаметром 3,5 мм нанесем точки, определяющие соответствующие экспериментальные значения: скорость витания сунгулита $v_{\mathrm{B}}=18,9 \mathrm{M} / \mathrm{c}$, оливин-пироксеновой породы $22,2 \mathrm{M} / \mathrm{c}$. 
Отношения этих значений к своим теоретическим значениям, полученным расчетом по формуле (1), и для сунгулита, и для оливин-пироксена составляет $k_{z}=1,16$. Введем этот эмпирический коэффициент в формулу (1) как корректировочный:

$$
v_{\mathrm{B}}=5,31 \cdot k_{\text {э }} \sqrt{D_{\mathrm{y}} \frac{\rho_{\mathrm{M}}}{\rho_{\mathrm{B}}}} .
$$

Формулу (2) можно использовать для расчетов скорости витания частиц-компонентов как откорректированную и более точную для данных материалов.

\section{Технология "холодного" дообогащения сунгулита}

Расчетная скорость потока в воздуховоде, обеспечивающая гарантированный унос частиц сунгулита, - это верхний предел из интервала:

$$
v_{\text {c.y }}=19,6 \mathrm{~m} / \mathrm{c} \text {. }
$$

Из рис. 3 видно, что это значение приближается к нижней границе диапазона скоростей для оливин-пироксеновой породы $(21,7 \mathrm{~m} / \mathrm{c})$. Это значит, что чистого «холодного» (до термообработки в печи) разделения сунгулита и оливин-пироксеновой фазы достигнуть не удастся. В частности, при скорости $v_{c . y}=19,6 \mathrm{~m} / \mathrm{c}$ (рис. 3) из шести частиц оливин-пироксена вместе с сунгулитом будет уноситься четыре частицы (т. $a$ ), а это примерно $66 . .67 \%$ от его общего количества. По соотношению числа частиц расчет слишком приблизительный.

Для дальнейшего анализа воспользуемся гистограммой распределения весовых остатков на проволочных ситах навеска оливин-пироксеновой породы в 0,232 кг. На рис. 5 показано процентное распределение остатков на лабораторных ситах С $12 / 38$ с размерами ячеек в свету: 1,$0 ; 1,25 ; 1,6$; 2,$0 ; 2,5 ; 3,2$ и 4,0 мм. Анализ гистограммы показал, что в общем массиве в небольшом количестве содержатся частицы менее 1,3 мм и более 3,5 .

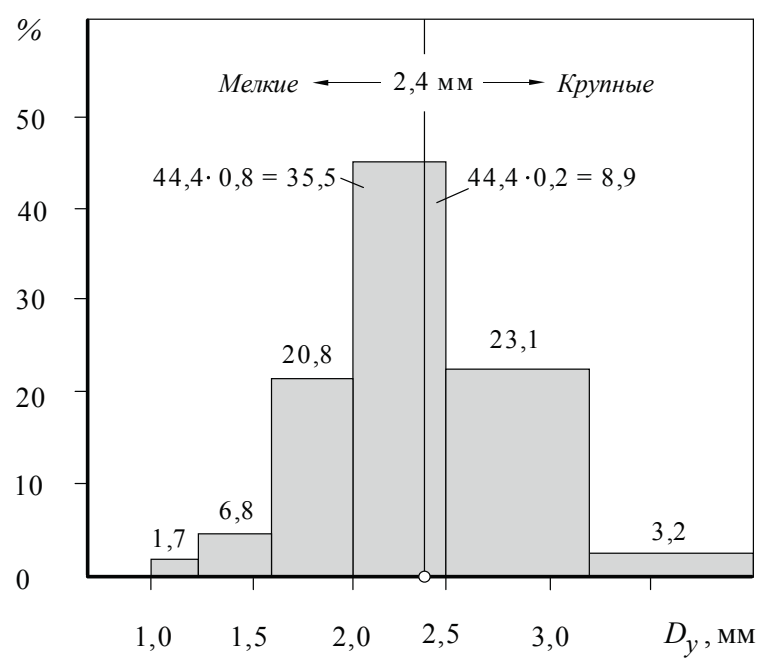

Pис. 5. Гистограллы весовых остатков оливин-пироксена на ситах с ячейками: 1,$0 ; 1,25 ; 1,6 ; 2,0 ; 2,5 ; 3,3 ; 4,0$ м.м

Fig. 5. Histograms of weight residues of olivine-pyroxene on screens with cells: 1,$0 ; 1,25 ; 1,6 ; 2,0 ; 2,5 ; 3,3 ; 4,0 \mathrm{~mm}$
Расчет суммарной массы мелких частиц (относительно 2,4 мм) дает значение 0,1503 кг, что составляет 64,8 \%, остальные 0,0817 кг - это масса крупных частиц (35,2%). Распределение весовых остатков расфракционированной навески сунгулита показало похожее соотношение мелких $(66,1 \%)$ и крупных $(33,9 \%)$.

Таким образом, вместе с сунгулитом будет уноситься примерно $65 \%$ по массе относительно частиц оливин-пироксеновой фазы от его общего количества.

Как отмечалось выше, в исходном конгломерате в среднем содержится:

- $35 \%$ вермикулита;

- $24 \%$ сунгулита;

- $41 \%$ оливин-пироксена.

Например, при общей массе исходного конгломерата 1000 кг масса оливин-пироксеновой фазы составит 410 кг, следовательно:

- вместе с сунгулитом будет унесено оливин-пироксеновой фазы:

$$
410 \cdot 0,65=266,5 \text { кг; }
$$

- после «холодного» обогащения будет выведено и утилизировано остальное:

$$
410-266,5=143,5 \text { кг. }
$$

В итоге в разделенном виде будет получено концентрата:

- вермикулитового - 350 кг;

- сунгулитового - 506,5 кг $(240+266,5)$.

При этом полученный концентрат будет содержать по массе 47,4 \% сунгулита.

Для увеличения концентрации целевого продукта проводится вторая технологическая операция - выделение крупных частиц сунгулита $(2,4$ мм и более) из общей массы в 506,5 кг на барабанном сите. Таким образом, из 47,4 -процентного концентрата будет выделено 81,4 кг сунгулита $(33,9 \%$ от 240 кг). Оставшаяся смесь частиц будет иметь общую массу 425,1 кг с содержанием:

- сунгулита - 158,6 кг (240-81,4);

- оливин-пироксеновой породы - 266,5 кг.

Концентрация сунгулита уменьшится и составит всего $35,1 \%$.

В результате второго технологического передела (фракционирования) из исходной массы в 1000 кг будет выделено целевых продуктов:

- 350 кг вермикулитового концентрата, который после обжига в печи (при коэффициенте вспучивания примерно 8,1 м³ ченного вермикулита;

- 81,4 кг сунгулита, который из-за потери примерно 17 \% химически связанной воды, как отмечалось выше, после термоактивации в печи даст 67,6 кг чистого магнезиально-силикатного реагента.

Третий этап технологии «холодного» дообогащения - повторное аэродинамическое разделение частиц-компонентов, но уже при других скоростях витания и уноса. В соответствии с зависимостями 3 и 4 (рис. 4) эти скорости будут определяться уже по 
условному диаметру частиц $D_{\mathrm{y}}=2,4$ мм и составят:

- для сунгулита $-v_{\text {с.в }}=16,2 \mathrm{M} / \mathrm{c}$;

- для оливин-пироксеновой породы $-\mathrm{v}_{\text {о.п.в }}=18,1 \mathrm{~m} / \mathrm{c}$.

Исходя из значений соотношений скорости витания и скорости отделения для частиц с условными диаметрами 3,5 мм:

- для сунгулита - 1,037;

- для оливин-пироксеновых частиц - 1,018 ;

рассчитаем скорости уноса частиц с $D_{\mathrm{y}}=2,4$ мм:

- для сунгулита $-v_{c . y}=16,8 \mathrm{~m} / \mathrm{c}$

- для оливин-пироксеновых и $v_{\text {о.п. }}=18,4 \mathrm{~m} / \mathrm{c}$.

Проанализируем зависимости (рис. 3) при значении скорости уноса частиц сунгулита $16,8 \mathrm{~m} / \mathrm{c}$. Построенная вертикальная линия определит точки пересечения $b$ и $c$ на зависимостях для сунгулита и оливин-пироксена. На правой оси ординат точке $b$ будет соответствовать значение количества отделенных и уносимых потоком воздуха частиц сунгулита, равное шести. На основании этого произведем разметку от нуля до шести. Точка $c$ определит значение числа частиц оливин-пироксеновой породы, которые будут унесены вместе с сунгулитовыми частицами - 3,45, а это примерно 57 \% от шести, что соответствует уносу 152 кг оливин пироксеновых частиц $(266,5 \cdot 0,57=152)$.

В результате третьей технологической операции будет отделено и утилизировано:

$266,5-152=114,5 \mathrm{\kappa г.}$

Полученная смесь частиц будет содержать:

- мелкой оливин-пироксеновой породы - 152 кг; - мелкого сунгулита - 158,6 кг.

При условном возвращении в эту смесь ранее отделенной фракционированием части сунгулита в 81,4 кг (всего сунгулита 158,6+81,4=240 кг) получим окончательно после всех операций «холодного» дообогащения сунгулитовый концентрат с содержанием:

- оливин-пироксеновой породы - 152 кг;

- сунгулита - 240 кг (при его массовой концентрации $61,2 \%$.)

\section{Энергетические аспекты}

Выполненные расчеты показывают, что качество получаемого сунгулитового концентрата можно признать хорошим по трем соображениям.

Во-первых, при сравнении содержания сунгулита по массе с его содержанием при отделении только вермикулита наблюдается хороший результат: 61,2 \% против $37 \%$ (240/650).

Во-вторых, при первой и третьей технологических операциях из исходного конгломерата будет выведено и утилизировано $143,5+114,5=258$ кг (63\% от 410 кг) оливин-пироксеновой породы без затрат тепловой энергии на ее обжиг в печи.

В-третьих, остается возможность дообогащения сунгулита после термической обработки в печи.

Оценим экономию тепловой энергии за счет выведения и утилизации оливин-пироксеновой породы.

В работе авторов [11] определены ориентировочные значения усвоенных тепловых энергий минералами, входящими в состав одного килограмма сунгулит-вермикулитового конгломерата с учетом температур их нагрева:

- вермикулита $-\theta_{\mathrm{B}}=211,6$ кДж;

- сунгулита $-\theta_{c}=160,5$ кДж;

- оливин-пироксена - $\theta_{\text {оп }}=282,6$ кДж.

Суммарное поглощение теплоты составило 654,7 кДж.

С учетом выделения и утилизации $61,2 \%$ оливин-пироксеновой породы, определим экономию тепловой энергии при дальнейшей термообработке минералов-компонентов конгломерата:

$$
\theta_{\text {э }}=0,41 \cdot 0,612 c_{\text {оп }} \cdot 0,95 m T_{\text {оп }},
$$

где 0,41 - массовая доля оливин-пироксеновой породы в конгломерате; $c_{\text {оп }}$ с средняя удельная теплоемкость оливин-пироксена (772 Дж/кг ${ }^{\circ} \mathrm{K}$ [21]); 0,95 - коэффициент, учитывающий потерю массы минерала за счет выхода физической воды (при $5 \%$ влажности); $m$ - масса исходного конгломерата $(1 \mathrm{\kappa г}) ; T_{\text {оп }}$ примерная средняя температура перегрева оливин-пироксена $\left(715{ }^{\circ} \mathrm{C}=988{ }^{\circ} \mathrm{K}[11]\right)$.

Расчет по формуле (3) дает значение экономии тепловой энергии $\theta_{2}=181,8$ кДж, что составляет $28 \%$ от суммарного поглощения теплоты 654,7 кДж.

Снижение удельной энергоемкости обжига вермикулитового и термоактивации сунгулитового концентратов после их «холодного» дообогащения также составляет $28 \%$. В абсолютных значениях это - 472,9 кДж/кг против 654,7 кДж/кг, что является хорошим результатом.

\section{Технологическое оборудование}

Опыт работы с вермикулитом показал, что даже качественные концентраты Ковдорского горнообогатительного комбината с регламентированным содержанием вермикулита $97 . . .98$ \% от партии к партии значительно отличаются. Иногда в некоторых партиях весом 56000...60000 кг вместе с вермикулитом идет существенное количество песка - до 7...9 \% по массе. Для переработки таких концентратов было опробовано аэродинамическое разделительное устройство, выполненное как насадок, установленный вместо затвора накопительного бункера (рис. 6$)$.

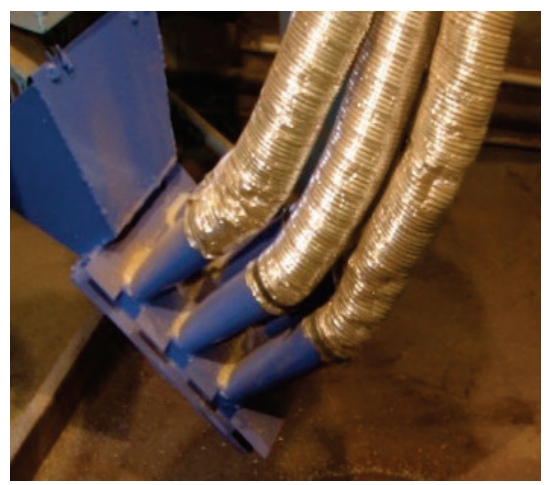

Pис.6. Экспериментальное аэродинамическое разделительное устройство

Fig. 6. Experimental aerodynamic separation device 
Испытания устройства на таких «запесоченных» концентратах показали положительный результат: при производительности электрической модульно-спусковой печи [11] по вспученному материалу $1,25 . . .1,5 \mathrm{~m}^{3} /$ ч вермикулит полностью выводился из общего массива.

В нашем случае разделению подлежали не вспученные компоненты, поэтому усовершенствованное устройство представляло собой более сложную конструкцию (рис. 7).

Аэродинамическое разделительное устройство содержит вертикальный канал - 1 коробчатого сечения, в который из дозатора поступает просушенный сунгулит-вермикулитовый конгломерат. Лопасти - 2 служат для направления потока сыпучего материала по нижней поверхности, в которой выполнены поперечные прорези - 3, пропускающие воздух в процессе работы устройства.

На верхней поверхности закреплены патрубки, имеющие фасонную форму. В нижней части (разрез $A-A$ ) сечение патрубка - 4 имеет плоскую скругленную форму, плавно переходящую в окружность, - патрубок - 5. При этом площади сечений патрубков - 4, 5 для отвода вермикулита $s_{1}$ и $s_{2}$ равны. Также равны между собой и площади сечений патрубков - 4, 5 для отвода сунгулита (но не равны между собой). Далее патрубки - 5 через отводы - 6 соединяются с вертикальными патрубками - 7. В нижней части устройства имеется выходной щелевидный канал -8 для выхода оливин-пироксеновой породы.

Патрубки - 4, отводящие сунгулит, несколько наклонены навстречу движущимся частицам, уже набравшим скорость вдоль нижней поверхности. При этом на входе в плоские патрубки - 4 скорость воздуха равна скорости уноса сунгулита $v_{\text {c.y }}=19,6 \mathrm{~m} / \mathrm{c}$, а в патрубках для отвода вермикулита скорость соответственно равна $v_{\text {в.у }}=11,0 \mathrm{~m} / \mathrm{c}$.

Настройка скоростей всасывания обеспечивается регуляторами мощности и шиберами вытяжных вентиляторов, входящих в состав установки (рис. 8).

Установка содержит аэродинамическое разделительное устройство -1, соединенное вертикальным каналом с дозатором сунгулит-вермикулитового конгломерата - 2. За счет вытяжных вентиляторов - 3, 4 в бункерах-осадителях $-5,6$ создается разряжение, степень которого регулируется шиберами в их всасывающих отверстиях (на рисунке не показаны) и дополнительно, для точной настройки скоростей $v_{\text {с.у }}$ и $v_{\text {в.у }}$ - регуляторами мощности самих вентиляторов. Благодаря разряжению в плоских патрубках - 4 (рис. 7) вермикулит, а затем и сунгулит с мелкими частицами оливин-пироксена высасываются из общего потока исходного конгломерата и, за счет резкого расширения пространства бункеров-осадителей при выходе из трубопроводов -7 и 8, выпадают внутрь. Бункер - 5 накапливает вермикулит, бункер - 6 - смесь сунгулита и оливин-пироксеновой породы, но большая часть последней выходит через щелевидный канал - 7 (рис. 7) аэродинамического устройства.

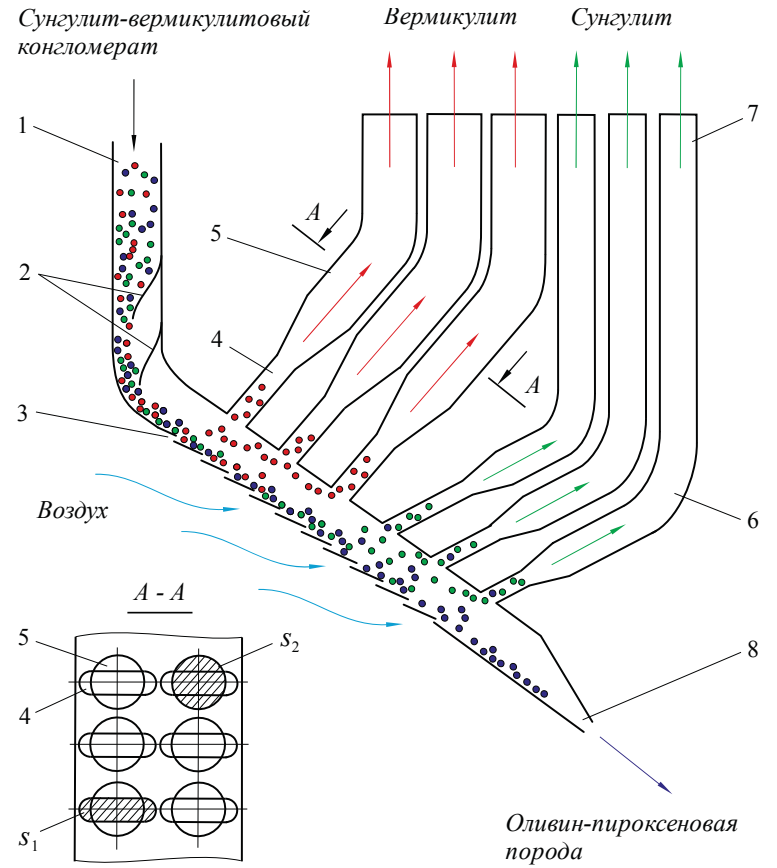

Pис. 7. Схема аэродиналического разделительного устройства: 1 - вертикальный канал; 2 - лопасти; 3 - прорези; 4, 5 патрубки; 6 - отводы; 7 - продуктопроводы; 8-выходной щелевидный канал

Fig. 7. Diagram of aerodynamic separation device: 1 is the vertical channel; 2 are the blades; 3 are the mortises; 4, 5 are the branch pipes; 6 are the bends; 7 is the supply pipeline; 8 is the output slotted channel

По мере наполнения бункеров-осадителей $-5,6$ их опорожняют, но лишь частично, чтобы не возникало просасывания воздуха через затворы, соединяющие их с приемными бункерами - 9, 10 (рис. 8). Далее материалы, накопленные в них, отправляют на термообработку в электрическую модульно-спусковую печь, функционирование которой в составе технологического комплекса рассмотрено в работе [22].

\section{Технология "горячего" дообогащения сунгулита}

Вернемся к сунгулитовому концентрату с отделенными фракционированием крупными частицами сунгулита при его содержании $35,1 \%$, в котором целевого продукта содержится 158,6 кг при общей массе материала 425,1 кг.

При термоактивации сунгулит теряет в массе в среднем $17 \%$, а это снижает его насыпную плотность до 852 кг/м. Так как насыпные плотности оливин-пироксеновой фазы и активированного сунгулита соответственно равны 1300 и 852 кг/ $\mathrm{M}^{3}$, то уменьшение исходной плотности целевого продукта - магнезиального реагента, будет составлять уже только $34,5 \%$.

Согласно графикам (рис. 3), можно выделить три критические точки, соответствующие скоростям уноса:

- вермикулита $-v_{\text {в.y }}=11,0 \mathrm{~m} / \mathrm{c}$;

- сунгулита $-v_{\text {c.у }}=19,6 \mathrm{~m} / \mathrm{c}$;

- оливин-пироксена $-v_{\text {о.п.у }}=22,6 \mathrm{~m} / \mathrm{c}$. 


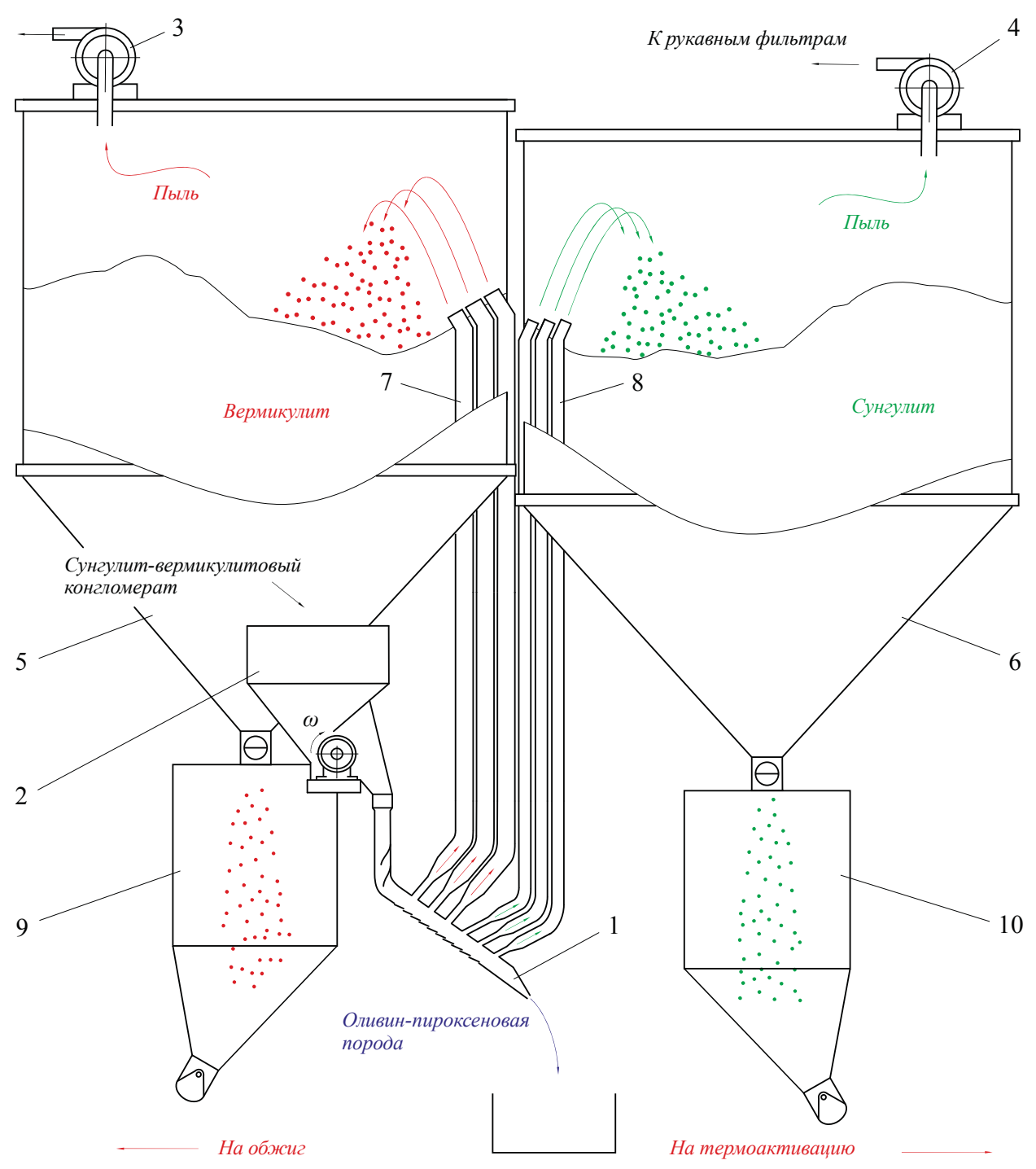

Рис.8. Установка для «холодного» дообогащения сунгулита

Fig. 8. Unit for «cold» re-preparation of sungulite

Для построения графиков зависимости скорости уноса частиц компонентов сунгулит-вермикулитового конгломерата от их насыпной плотности требуется значение плотности вермикулита-сырца. Данное значение было определено взвешиванием проб выделенных из исходного концентрата вермикулитовых частиц (рис. $1, a$ ) и составило $720 \mathrm{\kappa г} / \mathrm{M}^{3}$.

По трем точкам построен (интерполирован) график зависимости скорости уноса частиц-компонентов от их насыпной плотности (рис. 9).

Pис. 9. Зависимость скорости уноса частии от насыпной плот ности компонентов сунгулит-вермикулитового конгло мерата

Fig. 9. Dependence of the rate of entrained particles on bulk density of sungolite-vermiculite conglomerate components

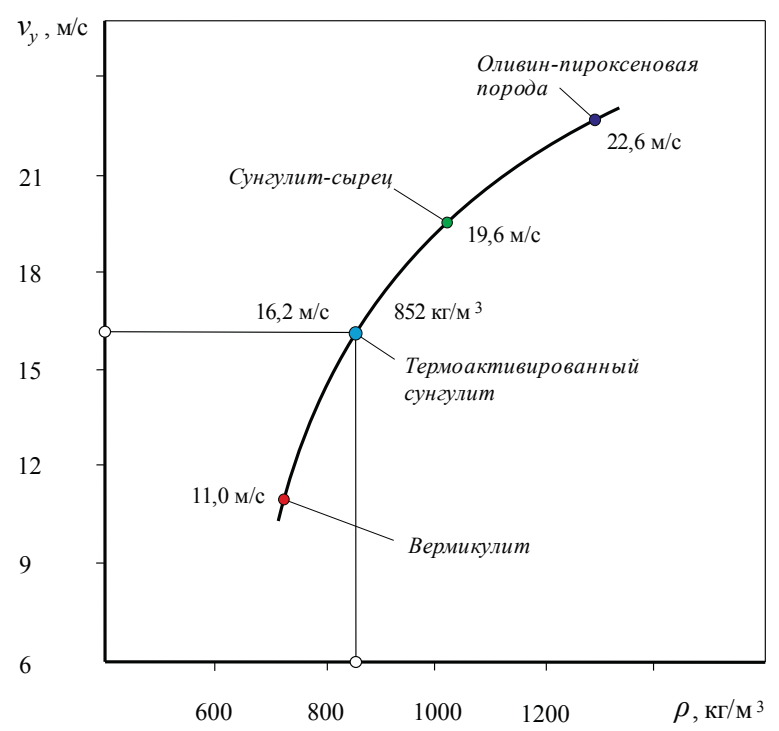


Для требуемого значения насыпной плотности термоактивированного сунгулита $\left(\rho=852 \kappa г / \mathrm{m}^{3}\right)$ определим ориентировочное значение скорости уноса его наиболее крупных частиц $\geq 3,5$ мм $v_{\text {т... }}=16,2 \mathrm{M} / \mathrm{c}$.

На рис. 10 показаны экспериментальные зависимости (рис. 3), адаптированные для определения скоростей уноса после термоактивации сунгулита и обжига оливин-пироксена (точки экспериментальных значений удалены).

График 2, соответствующий активированному сунгулиту, получен параллельным переносом графика 1 до критической точки с координатой $v_{\text {т...у }}=16,2 \mathrm{~m} / \mathrm{c}$.

На оси ординат (рис. 10) расположена правая по рис. 3 шкала «n, шт», хотя сами графики для сунгулита и оливин-пироксеновой породы не изменены. Теперь для частиц-компонентов с размерами меньше 2,4 мм скорость уноса термоактивированного сунгулита, определяемая, как и раньше, по шести частицам, может быть установлена положением точки $a$ на графике 2 :

$$
v_{\text {т.с. }}=13,0 \mathrm{~m} / \mathrm{c} \text {. }
$$

Данному значению скорости соответствует число частиц оливин-пироксена, унесенных вместе с частицами легкого сунгулита, - 0,5 (определяется положением точки б). Это значит, что после термической обработки и аэродинамического разделения всего 8,3\% $(100 \% \cdot 0,5 / 6)$ от общего количества сунгулитового концентрата будет составлять оливин-пироксеновая фаза.

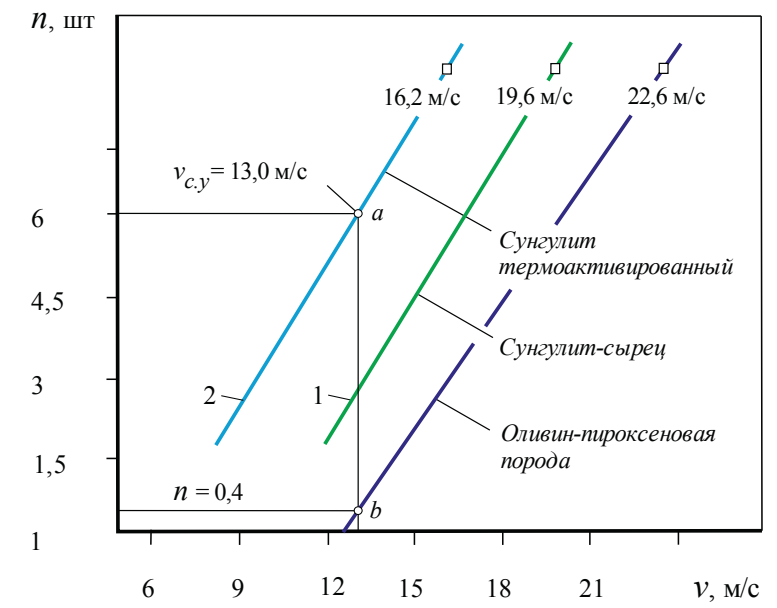

Рис. 10. Графики к определению скоростей уноса после терлоак тивации сунгулита и обжига оливин-пироксеновой фазы

Fig. 10. Graphs to determine the entrained rate after sungulite ther mal activation and heat-treatment burning olivine-pyroxene phase
В процессе «холодного» дообогащения и фракционирования была получена смесь частиц общей массой 425,1 кг с содержанием оливин-пироксеновой породы - 266,5 кг и сунгулита 158,6 кг при концентрации последнего всего 35,1 \% . Этот материал будет подвергнут термообработке. Масса активированного сунгулита из-за выхода химически связанной воды уменьшится на $17 \%$ и составит 131,6 кг $(158,6 \cdot 0,83)$. Вместе с тем оставшиеся в полученном концентрате 8,3 \% оливин-пироксена - это 22,1 кг $(0,083 \cdot 266,5)$, а общая масса концентрата составит $153,7(22,1+131,6)$.

В результате «горячей» технологической операции при последующем аэродинамическом разделении будет получен мелкий $(1,3 . .2,4$ мм) сунгулитовый концентрат с содержанием сунгулита $85,6 \%(100 \% \cdot 131,6 / 153,7)$.

Несмотря на то, что данные и ранее полученные значения являются прогнозными, так как точность расчетов не высока, в целом получены хорошие результаты.

\section{Заключение}

Результаты работы демонстрируют достижение цели исследования.

Усовершенствованная технология получения вермикулита и активированного сунгулита из горно-промышленных отходов Ковдорского флогопит-вермикулитового месторождения станет менее энергоемкой. На переработку одной тонны сунгулит-вермикулитового конгломерата потребуется 472,9 мДж вместо прежних 654,7 мДж [11], т. е. на $28 \%$ меньше.

В результате применения дополнительных технологических операций: первичного аэродинамического разделения компонентов, фракционирования, повторного аэродинамического разделения, но уже при других скоростях витания и окончательного разделения после термической обработки, из одной тонны конгломерата может быть получено:

- 350 кг вермикулита-сырца или 2,84 м³ вспученного продукта;

- 67,6 кг чистого магнезиально-силикатного реагента с размерами зерен $2,4 \ldots 3,5$ мм;

- 157,7 кг сунгулитового концентрата в термоактивированном виде с зернами 1,3...2,4 мм при концентрации 85,6 \% .

Новый энергосберегающий технологический комплекс по переработке сунгулит-вермикулитовых конгломератов, рассмотренный в работе авторов [11], реализующий эту усовершенствованную технологию выделения целевых продуктов, дополнится лишь установками аэродинамического дообогащения и фракционирования. 


\section{СПИСОК ЛИТЕРАТУРЫ}

1. Fan Ding et al. Tuning wettability by controlling the layer charge and structure of organo-vermiculites / Journal of Industrial and Engineering Chemistry. - 2018. - V. 57. - P. 304-312.

2. Figueiredo S. The influence of acid treatments over vermiculite based material as adsorbent for cationic textile dyestuffs // Chemosphere. - 2016. - V. 153. - P. 115-129.

3. Fuks L., Herdzik-Koniecko I. Vermiculite as a potential component of the engineered barriers in low- and medium-level radioactive waste repositories // Applied Clay Science. - V. 161. 2018. - P. 139-150.

4. Kariya J., Ryu J., Kato Y. Development of thermal storage material using vermiculite and calcium hydroxide // Applied Thermal Engineering. - 2016. - V. 94. - P. 186-192.

5. Incorporation of expanded vermiculite lightweight aggregate in cement mortar / Kim Hung Mo, Hong Jie Lee, Michael Yong Jing Liu, Tung-Chai Ling // Construction and Building Materials. 2018. - V. 179. - P. 302-306.

6. Sevim İşçi. Intercalation of vermiculite in presence of surfactants //. Applied Clay Science. - 2017. - V. 146. - P. 7-13.

7. Sevim Isş̧i, Yavuz İşçi. Characterization and comparison of ther mal \& mechanical properties of vermiculite polyvinylbutyral nanocomposites synthesized by solution casting method // Applied Clay Science. - 2017. - V. 151. - P. 189-193.

8. Кременецкая И.П., Корытная О.П., Васильева Т.Н. Реагент для иммобилизации тяжелых металлов из серпентинсодержащих вскрышных пород // Водоочистка. Водоподготовка. Водоснабжение. - 2008. - № 4. - С. 33-40.

9. Выделение вермикулитового концентрата из хвостов обогащения вермикулитовых руд и его использование в жаростойком бетоне / А.Ш. Гершенкоп, М.С. Хохуля, 0.Н. Крашенинников и др. // Горный журнал. - 2011. - № 11. - С. 57-59.

10. Аморфизация серпентиновых минералов в технологии получения магнезиально-силикатного реагента для иммобилизации тяжелых металлов / И.П. Кременецкая, А.Т. Беляевский, Т.Н. Васильева и др. // Химия в интересах устойчивого развития. - 2010. - № 18. - С. 41-49.

11. Нижегородов А.И., Гаврилин А.Н., Мойзес Б.Б. Применение и технология получения продуктов термоактивации серпентиновых минералов из промышленных отходов // Известия Том- ского политехнического университета. Инжиниринг георесурсов. -2018 . - Т. 329 . - № 5. - С. $67-73$.

12. Направления комплексного использования отходов добычи флогопита / С.В. Терещенко, И.П. Кременецкая и др. / / Экологическая стратегия развития горнодобывающей отрасли: сборник докладов Всеросс. науч. техн. конф. В 2 т. - Апатиты; СПб.: Реноме, 2014. - T. 1. - С. 272-279.

13. Звездин А.В. К технологии получения сунгулитовых и вермикулитовых концентратов из вскрышных пород Ковдорского флогопит-вермикулитового месторождения // Вестник ИрГТУ. - 2015. - № 8. - С. 93-99.

14. Вибрации в технике: справочник в 6-ти т. Т. 4. Вибрационные процессы и машины / под ред. Э.Э. Лавендела. - М.: Машиностроение, 1981. - 509 с.

15. Harris C.M., Piersol A.G. Harris' shock and vibration handbook. - New York: McGraw-Hill Professional, 2002. - 1460 p.

16. Ahirrao N.S., Bhosle S.P., Nehete D.V. Dynamics and Vibration Measurements in Engines // Procedia Manufacturing. - 2018. V. 20. - P. 434-439.

17. Rashad A.M. Vermiculite as a construction material - A short guide for Civil Engineer // Construction and Building Materials. V. 125. - 2016. - P. 53-62.

18. Industrial minerals \& rocks: commodities, markets, and used / ed. by J.E. Kogal. - Littleton: Society for Mining, Metallurgy, and Exploration, Inc., 2006. -1529 p.

19. Вайнсон А.А. Подъемно-транспортные машины. - М.: Машиностроение, 1974. - 431

20. Горная энциклопедия. URL: http://www.mining-enc.ru (дата обращения 25.06.2018).

21. Физические свойства горных пород и полезных ископаемых (петрофизика). Справочник геофизика / под ред. Н.Б. Дортмана. - М.: Недра, 1984. - 455 с.

22. Нижегородов А.И., Гаврилин А.Н., Мойзес Б.Б. Технологический комплекс для переработки вермикулитовых концентратов и конгломератов // Известия Томского политехнического университета. Инжиниринг георесурсов. - 2018. - Т. 329. № 11. - C. 74-86.

Поступила 12.11.2018 2.

\section{Информация об авторах}

Нижегородов А.И., доктор технических наук, профессор кафедры строительных, дорожных машин и гидравлических систем Иркутского национального исследовательского технического университета.

Гаврилин A.H., кандидат технических наук, доцент отделения материаловедения Инженерной школы новых производственных технологий Национального исследовательского Томского политехнического университета.

Мойзес Б.Б., кандидат технических наук, доцент отделения контроля и диагностики Инженерной школы неразрушающего контроля и безопасности Томского политехнического университета. 
UDC 622.23.05; 67.05; 66.041

\title{
IMPROVING THE TECHNOLOGY FOR PROCESSING SUNGULITE-VERMICULITE CONGLOMERATES
}

\author{
Anatoly I. Nizhegorodov' \\ nastromo_irkutsk@mail.ru
}

\author{
Alexey N. Gavrilin², \\ tom-gawral@list.ru \\ Boris B. Moyzes², \\ mbb@tpu.ru \\ 1 Irkutsk National Research Technical University,
83, Lermontov Avenue, Irkutsk, 664074, Russia. \\ ${ }^{2}$ National Research Tomsk Polytechnic University, \\ 30, Lenin Avenue, Tomsk, 634050, Russia.
}

Relevance. The improved energy and resource-saving technology, implemented in new technological complexes with preliminary «cold» re-preparation, allows returning valuable raw material resources to industrial circulation and obtaining vermiculite and sugulite concentrates from mining waste accumulated in the Kovdor flogopit-vermiculite deposit. Therefore, this work is devoted to the issues of improving the processing of sungulite-vermiculite conglomerates.

The aim of the research is to analyze the possibility of improving the technology for producing thermally activated sungulite and expanded vermiculite from mining wastes of the Kovdor phlogopite-vermiculite deposit and increasing its energy efficiency.

The object of the research is the technological equipment for processing sungulite-vermiculite conglomerates, which implements energy- and resource-saving technology for producing activated sungulite and vermiculite concentrate.

The methods are based on the experimental data and analysis of aerodynamic separation of vermiculite and sungulite from olivine-pyroxene rock and increase of allotment of sungulite in sungulite concentrate.

The results prove the aim of the research is achieved. On their basis, it is possible to develop the improved technology for vermiculite producing, including expanded and magnesia-silicate reagent (thermoactivated sungulite) from mining industrial wastes with energy savings of up to $182 \mathrm{~kJ} / \mathrm{kg}$, which reduces energy consumption of their processing by $28 \%$ compared to the previous technology. Besides, additional technological operations make it possible to obtain $350 \mathrm{~kg}$ of raw vermiculite, $68 \mathrm{~kg}$ of pure magnesia-silicate reagent with grain sizes of 2,4...3.5 $\mathrm{mm}$ and $158 \mathrm{~kg}$ of sungulite concentrate in a thermo-activated form with grains of 1,3...2,4 mm at almost 86 percent concentration. In general, we can conclude that the continuation of work in the field of development and improvement of technologies for processing sungulite-vermiculite conglomerates is promising.

\section{Key words:}

Sungulite-vermiculite conglomerates, sungulite, vermiculite, pyroxene-olivine rock, thermo-activation, burning process, components separation, soaring speed, technological complex, "cold» re-preparation, heat energy.

\section{REFERENCES}

1. Fan Ding. Tuning wettability by controlling the layer charge and structure of organo-vermiculites. Journal of Industrial and Engineering Chemistry, 2018, vol. 60, pp. 304-312.

2. Figueiredo $\mathrm{S}$. The influence of acid treatments over vermiculite based material as adsorbent for cationic textile dyestuffs. Chemosphere, 2016, vol. 153, pp. 115-129.

3. Fuks L., Herdzik-Koniecko I. Vermiculite as a potential component of the engineered barriers in low- and medium-level radioactive waste repositories. Applied Clay Science, 2018, vol. 161, pp. $139-150$.

4. Kariya J., Ryu J., Kato Y. Development of thermal storage material using vermiculite and calcium hydroxide. Applied Thermal Engineering, 2016, vol. 94, pp 186-192.

5. Kim Hung Mo, Hong Jie Lee, Michael Yong Jing Liu, Tung-Chai Ling. Incorporation of expanded vermiculite lightweight aggregate in cement mortar. Construction and Building Materials, 2018, vol. 179, pp 302-306.

6. Sevim İşçi. Intercalation of vermiculite in presence of surfactants. Applied Clay Science, 2017, vol. 146, pp. 7-13.

7. Sevim İşci, Yavuz İşi. Characterization and comparison of thermal \& mechanical properties of vermiculite polyvinylbutyral nanocomposites synthesized by solution casting method. Applied Clay Science, 2017, vol. 151, pp. 189-193.
8. Gershenkop A.Sh., Khokhulya M.S., Krasheninnikov 0.N., Bastrygina S.V. Allocation of vermiculite concentrate from tailings of vermiculite ores and its use in heat-resistant concrete. Gorny zhurnal, 2011, vol. 11, pp. 57-59. In Rus.

9. Kremenetskaya I.P., Korytnaya O.P., Vasileva T.N. Reagent dlya immobilizatsii tyazhelykh metallov iz serpentinsoderzhashchikh vskryshnykh porod [Reagent for immobilization of heavy metals from serpentineros overburden]. Vodoochistka. Vodopodgotovka. Vodosnabzhenie, 2008, vol. 4, pp. 33-40.

10. Kremenetskaya I.P., Belyaevskiy A.T., Vasileva T.N., Korytnaya 0.P., Makarova T.I. Amorphization of serpentine minerals in production of magnesia-silicate reagent for immobilization of heavy metals. Chemistry for Sustainable Development, 2010, vol. 18, pp. 41-49. In Rus.

11. Nizhegorodov A.I., Gavrilin A.N., Moyzes B.B. Application and production technology of thermal activation products of serpentine minerals from industrial wastes. Bulletin of the Tomsk Polytechnic University. Geo Assets Engineering, 2018, vol. 329, no. 5, pp. 67-75. In Rus.

12. Tereshchenko S.V., Alekseeva S.A., Rukhlenko E.D., Kremenetskaya I.P., Bastrygina S.V., Ivanova L.A. Napravleniya kompleksnogo ispolzovaniya otkhodov dobychi flogopita [Directions of comprehensive utilization of phlogopite waste]. Ekologicheskaya strategiya razuitiya gornodobyvayushchey otrasli. Sbornik do- 
kladov Vserossiyskoy nauchnotekhnicheskoy konferentsii [Proc. of All Russian scientific conference. Ekologicheskaya strategiya razvitiya gornodobyvayushchey otrasli]. Apatity; Saint-Petersburg, Renome Publ., 2014. Vol. 1, pp. 272-279.

13. Zvezdin A.V. Technology for obtaining sungulite and vermiculite concentrates from overburden rocks of the Kovdor phlogopite vermiculite deposit. Vestnik ISTU, 2015, vol. 8, pp. 93-99. In Rus.

14. Vibratsii v tekhnike: spravochnik. T. 4. Vibratsionnye protsessy $i$ mashiny [Vibration in engineering: handbook. Vol. 4. Vibration processes and machines]. Ed. by E.E. Lavendel. Moscow, Mashinostroenie Publ., 1981. 509 p.

15. Harris C.M., Piersol A.G. Harris' shock and vibration handbook. New York, McGraw-Hill Professional, $1460 \mathrm{p}$.

16. Ahirrao N.S., Bhosle S.P., Nehete D.V. Dynamics and Vibration Measurements in Engines. Procedia Manufacturing, 2018, vol. 20 , pp. 434-439.

17. Rashad A.M. Vermiculite as a construction material - a short guide for Civil Engineer. Construction and Building Materials, 2016, vol. 125 , pp. 53-62.

\section{Information about the authors}

Anatoly I. Nizhegorodov, Dr. Sc., professor, Irkutsk National Research Technical University.

Alexey N. Gavrilin, Cand. Sc., associate professor, National Research Tomsk Polytechnic University.

Boris B. Moyzes, Cand. Sc., associate professor, National Research Tomsk Polytechnic University.
18. Industrial minerals \& rocks: commodities, markets, and used. Ed. by J.E. Kogal. Littleton, Society for Mining, Metallurgy, and Exploration, Inc., 2006. 1529 p.

19. Vajnson A.A. Podemno-transportnye mashiny [Hoisting and transport machines]. Moscow, Mashinostroenie Publ., 1974. $431 \mathrm{p}$.

20. Gornaya entsiklopediya [Mountain encyclopedia]. Available at: http://www.mining-enc.ru (accessed 25 June 2018).

21. Fizicheskie svoystva gornykh porod i poleznykh iskopaemykh (petrofizika). Spravochnik geofizika [Physical properties of rocks and minerals (petrophysics). Handbook of Geophysics]. Ed. by N.B. Dortman. Moscow, Nedra Publ., 1984. 455 p.

22. Nizhegorodov A.I., Gavrilin A.N., Moyzes B.B., Kuvshinov K.A. Technological complex for vermiculite concentrates and conglomerates processing. Bulletin of the Tomsk Polytechnic University, Geo Assets Engineering, 2018, vol. 329, no. 11, pp. 74-86. In Rus.

Received: 12 November 2018. 